\title{
Criteria for integration of new structures in the conservation and restoration of adobe ruins: the temple of the ex-mission of Cocóspera in Sonora, México
}

\author{
L. F. Guerrero Baca \& F. J. Soria López \\ División de Ciencias y Artes para el Diseño, \\ Universidad Autónoma Metropolitana - Unidad Xochimilco, México
}

\begin{abstract}
This paper describes the problems encountered in the conservation of heritage property built with adobe, specifically those in an advanced ruinous condition. In spite of the development and application of diverse modern techniques to protect and consolidate adobe ruins from environmental factors, their deteriorating process has not been stopped. It seems as if the only way to preserve adobe structures has to do with the restitution of the whole constructive system of which it is a part. However the restitution of lost elements must avoid reconstruction processes that can jeopardize the buildings' authenticity. It is here where architectural integration plays a major role in the restoration of heritage buildings in a ruinous state. This paper explains the concepts of authenticity and integration and describes the criteria established for the restoration project of an ancient adobe temple in northern México in order to save its last vestiges.

Keywords: cultural heritage conservation, authenticity, architectural integration, architectural restoration, adobe conservation.
\end{abstract}

\section{Introduction}

Architecture that is built with soil is one of the oldest building traditions used by different cultures throughout history. Taking advantage of the natural resources available in the surrounding environment of buildings is not a very common practice in modern architecture, but this context-based constructive logic is constantly found in buildings of the past. 
Soil, particularly that used to fabricate adobe bricks, is a millenary material of excellent properties for constructing buildings well-adapted to the natural and cultural settings where they are erected. It is possible to find this kind of structures built many centuries ago, that in spite of the combined actions of man and environmental conditions have prevailed until today. However, its conservation and, consequently, its durability depend almost completely on maintaining in good state the complete constructive system. The moment that the adobe itself is exposed to atmospheric conditions it becomes a short-lasting material, easily becoming a ruin almost immediately.

In the last few decades many techniques have been applied in order to preserve adobe structures in ruinous state. They include artificial resins, cement, natural polymers, as well as protective barriers of all sizes and types. Nevertheless, the accelerated deterioration of adobe ruins in general has not been avoided; at most, the process has been slowed down. To date, it seems that the only way to conserve adobe structures is to restore the original constructive system as a whole. However when we involve buildings of a great historical value, which are in themselves documents that carry information of past ways of life, maintaining their authenticity becomes a major issue in order to establish intervention criteria.

The restoration of the temple of the ex-mission founded by Jesuits in Cocóspera, in the northern region of México, proposes an intervention which uses similar building techniques to those used for the original structure, but at the same time, clearly differentiated, in order to protect the historic document, that is the buildings authenticity.

\section{Conservation and authenticity}

In the field of cultural heritage conservation, much has been written and discussed over the importance that authenticity of cultural objects have, not only as we receive them from the past, but how we must leave them to future generations. This preoccupation obeys our need of being certain that the information held by documents from the past is trustful, which allows us to understand and interpret in a better way our history, a right that future generations are also entitled to. This intention was clearly established in the Nara Document on Authenticity since 1994: "Conservation of cultural heritage in all its forms and historical periods is rooted in the values attributed to the heritage. Our ability to understand these values depends, in part, on the degree to which information sources about these values may be understood as credible or truthful. Knowledge and understanding of these sources of information, in relation to original and subsequent characteristics of the cultural heritage, and their meaning, is a requisite basis for assessing all aspects of authenticity" [1].

The built environment, particularly architecture, is a cultural object that represents the society which produces them in a very detailed manner. It is much more than matter, stone over stone. They are forms that through social use, acquire sense, and they mean something. In other words, the conservation of architecture is not limited to its physical preservation, it must also include those 
intangible aspects it contains, the symbolism it represents, the remembrance it brings, the history it tells, the technology it describes. Together form and use, matter and energy, space and time, constitute an inseparable part of the object, which is verified through our subjective perception and experience and then becomes part of our collective heritage and memory. The important thing in conservation is not so much in how to do it, but why we do it, the reasons that makes it worthwhile: "The quest for the 'message' of cultural properties requires us to identify the ethical values, social customs, beliefs or myths of which physical heritage is the sign, the expression, in time and space. Values of authenticity or identity are advanced in order to reveal the significance of architectural or urban constructions and transformation of the natural landscape through human intervention. In the end, the concept or social representation of the cultural property is more important than the object itself: the intangible dimension prevails" [2].

From this point of view cultural heritage conservation must have a holistic approach. The signs, the footprints have to be preserved, but also the memory they represent. To achieve the former there are many strategies that, all together, help keep alive the remembrance of what has been; activities that include the identification, divulgation, education, investigation, protection (be it physical or legal), maintenance, and of course, in extreme cases, restoration of the cultural property in order to avoid its loss. Conserving our cultural heritage implies keeping its authenticity and respect for each stage of its evolution, including the contribution of our own time.

\section{Integration in architectural restoration}

Restoration implies an operation that is usually of urgent need, that is, the physical intervention of the cultural property is necessary, in order to avoid the possibility of losing it forever. The intervention of architecture, when it is at risk, had already been explained in the Venice Charter "The process of restoration is a highly specialized operation. Its aim is to preserve and reveal the aesthetic and historic value of the monument and is based on respect for original material and authentic documents" [3]. This document defines at the same time the main activities that allow its development: revealing, consolidation, reassembling and integration.

It is precisely integration, the operation of the restoration process, that has its sole main objective to safeguard that respect for original material, through the incorporation of new components. When we talk about integration of new elements, we are referring, on one hand, to those new objects or portions that substitute the original parts that have disappeared and allow recovering the original structures, volumes, or spaces, aimed towards a better comprehension and use of our cultural property.

These elements that are incorporated must be clearly distinct as new components, to avoid distortions of the cultural property as historic and artistic documents. In this sense the Venice Charter is quite accurate when it establishes that "any extra work which is indispensable must be distinct from the 
architectural composition and must bear a contemporary stamp." And furthermore it specifies how missing parts should be treated: "Replacements of missing parts must integrate harmoniously with the whole, but at the same time must be distinguishable from the original so that restoration does not falsify the artistic or historic evidence" [3]. The problem is that the restitution of lost parts many times become recreations or reconstructions of architecture.

Conservation of cultural heritage must not only include the technical and material aspects of restoration, but also and, in a fundamental way, consider its use - how contemporary society will live and inhabit these buildings and spaces made in the past, but with present expectations and habits. This last factor, the use or reuse of cultural heritage, has gained much importance in recent years. Heritage buildings require being adapted to current needs of the community. The use becomes an indispensable issue in order to guarantee the conservation of a building in the long term.

In this way, integration must not only refer to lost parts of a monument, but also to the inclusion of different elements that the building never had before, but that are needed for its current use, that is, for its own preservation in time. In other words, we may define integration as the distinct incorporation of new elements to the cultural property, indispensable for its conservation and that respect all its original parts and characteristics.

This respect means finding the correct balance between the new and the old. This is one of the challenges in heritage conservation that consists in creating a contemporary architecture, of our own time, and at the same time giving continuity to those inherited values, avoiding senseless recreations, or creating elements without consideration to their context. This is obviously a collective task, a shared responsibility by all members of society, never a unilateral decision: "Decision-making for interventions and contemporary architecture in a historic urban landscape demand careful consideration, a culturally and historic sensitive approach, stakeholder consultations and expert know-how. Such a process allows for adequate and proper action for individual cases, examining the spatial context between old and new, while respecting the authenticity and integrity of historic fabric and building stock" [4].

\section{The restoration of the temple at Cocóspera}

\subsection{Historical background and present state of conservation}

The ruins of the mission of Cocóspera are located near the Mexican border with the United States, in the Sonoran desert. It was founded in 1698 by the Jesuit father Francisco Eusebio Kino as a part of a complex network of civil and religious structures created to inhabit and dominate this inhospitable territory back in colonial times [5].

By the end of the $18^{\text {th }}$ century the Jesuits were expelled from all Spanish territories and all their buildings in the region were passed on to be managed by the Franciscan order [6]. Nevertheless they were not able to reestablish local production and population rates kept falling. Also the constant attacks of 
Apaches and Janos Indians continued until one of their incursions in 1776 detonated the need of practically erecting a new building in 1788 [7].

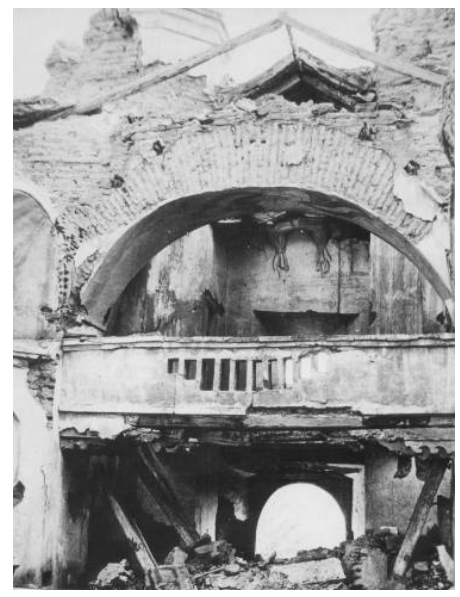

Figure 1: Interior view of the choir in the 1920's.

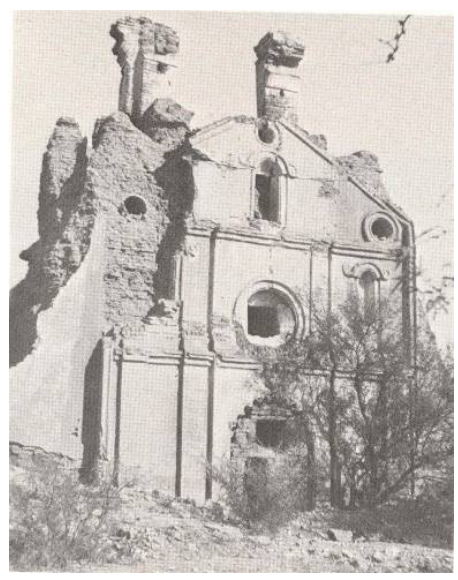

Figure 2: The main facade of the temple in 1920.

The Franciscan intervention goes beyond the sole repair of the structure. They decide to encapsulate the existing adobe walls with adobe and brick additions as well as lime mortar for the exterior and gypsum plaster in the interior.

A group of American travelers visited the missions founded by father Kino, back in 1830 and described the abandoned situation that prevailed then in Coscóspera [8]. Another notice about the temple appears in 1851, that describes the temple is unoccupied but in good general conditions, even preserving most of the interior decorations and even part of its furniture [9]. Thirty years later an earthquake occurred, which, in addition to the lack of maintenance throughout the years, caused great damage to the structure.

In the 1970's the institutional intervention of this monument begins to rescue and conserve the remaining ruins of Cocóspera. Since 1978 the site has had a permanent caretaker designated by the National Institute of Anthropology and History (INAH).

As part of this Project, a series of preliminary activities were developed in order to register and understand in a detailed manner the conditions and degree of conservation in which the ruins are to date and that are summarized as follows:

- Foundations: They are well preserved and with no evident damage in their internal composition or transmitted to the superstructure. The foundations are considered to be in good and safe working conditions and are able to continue supporting the temples' structure. 
- Walls: They are highly deteriorated and must be consolidated as soon as possible. There is no danger of collapse because of the width $(2.7 \mathrm{mts}$.) of the walls and also due to the fact that their original height has been drastically diminished. However their exposure to environmental conditions is totally inadequate, where the combined action of water, wind, sun and temperature changes will continue to erode and degrade the adobe walls. Immediate actions of consolidation and protection are required. The tests made to the adobe bricks revealed a good load bearing capacity of 10 $\mathrm{kg} / \mathrm{cm}^{2}$, which is above the usual standard of $9 \mathrm{~kg} / \mathrm{cm}^{2}$. Similarly its capacity to breaking effect was $5 \mathrm{~kg} / \mathrm{cm}^{2}$. The composition of the adobe was calculated by sedimentation process, which indicated that the original building material has $19 \%$ clay, $37 \%$ silt and $47 \%$ of sand and gravel, which gives the adobe a very adequate consistence and internal cohesion [10].

- Facades: The critical point as far as stability is concerned, is the main facade. This part of the building has many problems: loss of its verticality- it is leaning outwards; there is not an adequate binding between the brick facade built by Franciscans and the adobe wall built by the Jesuits; it has many horizontal cracks dividing the facade in various blocks that are unstable.

- Towers: The bases of the towers that were added to the building by the Franciscans have two main problems: on one hand, loss of mass and erosion and on the other, inadequate binding with the former Jesuit walls, generating a joint that does not have enough space for both elements to work independently.

- Roof: Almost all traces of the original roof systems have disappeared. The lack of this element has had a tremendous effect on the deterioration process of the building as a whole. Obviously the main problem is the exposure of the adobe structure to environmental factors, but it is not the only one. Without the roof the "head" of the walls are not connected and have an isolated structural behavior.

- Wall finish and paint Most of the lime plaster that covered the wall on the exterior facades has disappeared, leaving the adobe without protection. The interior of the temple was plastered with gypsum that is separating from the walls but must be preserved because it still has original decorative motifs.

- Floors: The original brick tiles used as floors in the interior are covered with thick stratus of material that came from the towers, roof and wall that have collapsed over the years and suffered important damages. It was possible to know how the original floor was built thanks to the archeological explorations that were made.

\subsection{Intervention criteria}

It is never easy to define how to conserve and restore our cultural heritage, specially, as in the case, when the buildings present an advance process of deterioration and decay, but simultaneously constitute a scarce resource of great 

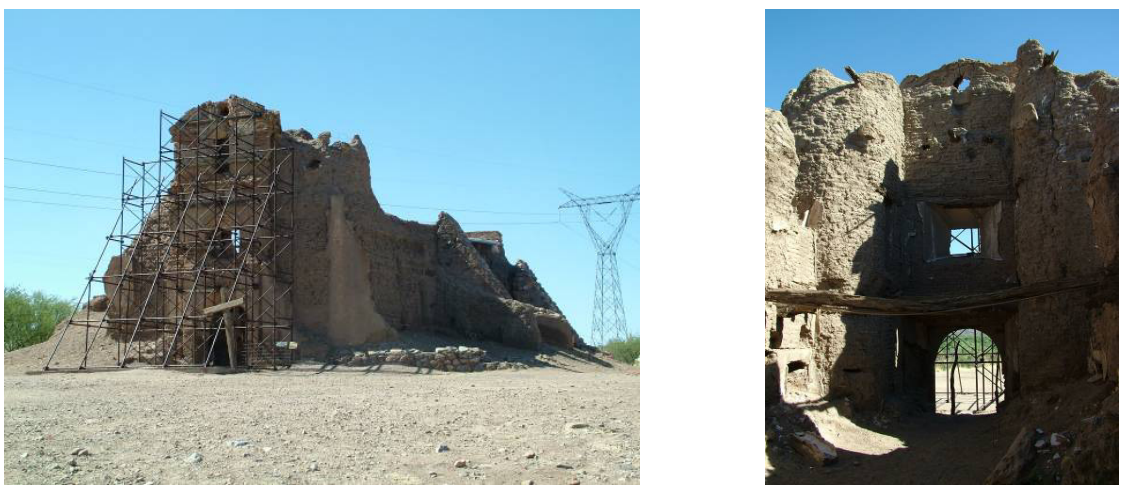

Figure 3: View of the $18^{\text {th }}$ century ruins of the temple built by Jesuits and Franciscans in Cocóspera, Sonora.

historical value for the community and the region, which makes the intervention a delicate and, at the same time, urgent need. Our approach to the Project, for the restoration of the temple of Cocóspera, departs from five basic principles that have been used to guide the proposal:

- Authenticity: As it was mentioned earlier, the main factor that determines the whole intervention is the special care for all the remaining elements of this temple. This magnificent building is one of the very few original structures that still survive of the whole mission network. Protecting its authenticity not only in its material aspects, but also its importance as a historical document, is a must. Any reconstruction should be discarded, and all complements and additions that are necessary for its conservation should be clearly distinguishable from the original elements. An archeological criterion has been followed throughout the architectural restoration project.

- Permanent Intervention: One of the main problems that the temple of Cocóspera has encountered in the past 30 years is the partial interventions, projects and preservation proposals. These actions helped to conserve or protect a specific element that was in great risk of disappearing, actions that contributed in that moment in time, but over the years have become in and of themselves inadequate. An integral project is needed, one that includes the conservation of all original parts, their permanent protection and inclusion in the constructive system as a whole. At the same time it should consider the use of the temple in a functional, safe and attractive way for all the community, as well as visitors.

- Integration of all new elements: All environmental, historic, social, aesthetic, technical and material aspects that characterize the site must be respected in their tangible and intangible features. The incorporation of all new elements either to substitute lost parts, or for the correct adaptation to contemporary use, can only be done within the principle of architectural integration, that is, that all new components become part of the whole, in a 
harmonious and balanced way. This integration must be considered at all scales.

- Compatible materials and techniques: It will be necessary to appeal to traditional knowledge to restore the temple, using the same materials and technical processes to insure the conservation of the building in the long term. At the same time the ruinous state of the structure and some flaws in the original design, as well as modern use, make it necessary to incorporate new technology that must be compatible with the original structure which understands the logic and specific behavior of the system as a whole.

- Reversibilit: This principle will be applied to most new elements, that is, to have the possibility to retrieve any added part, without damaging the original building as it is now days. This premise can not include the consolidation process of adobe walls, or elements such as the main facade, that require definite and permanent actions of consolidation and protection. The idea of reversibility also has to do with future use, new adaptations to social needs without damaging the cultural property.

\subsection{Architectural integration proposal}

The restoration Project for the temple of Cocóspera makes the following proposals intended to safeguard the physical and material ruins, but also the its historic value and the appropriate use of the building:

- The project establishes two lines of action: in the first place the ruinous character of the building must prevail, in other words it is part of its history and inseparable of its authenticity. On the other hand the building must be covered in order to be protected. The proposal is to restore the main elements the building lost, recovering the general volume and exterior scale based on the graphic documents as well as the information recovered by exploring the building itself. The main idea is to integrate a contemporary roof system, very neutral, and that recovers some of the main elements of the original roof, that is form, rhythm, structure logic. The exterior image will recover general characteristics as height, form, scale, volume.

- The walls must be restored in order to be able to support the new roof. This consolidation process will be done with adobe bricks, with a different size as well as adding a minimum proportion of lime (2-3\%) that will make a subtle texture and color difference compared to the original ones. In addition to the size and color of bricks, the width of the wall will diminish, having only $1.60 \mathrm{mts}$. instead of the $2.70 \mathrm{mts}$. of the combined Jesuit and Franciscan walls. The new adobe wall will be constructed on the outer side of the original wall, with the intention to restore the outside lines of the building, but leaving the ruinous character in the inside. This also has the intention to lighten the weight of the new structure over the original one. 

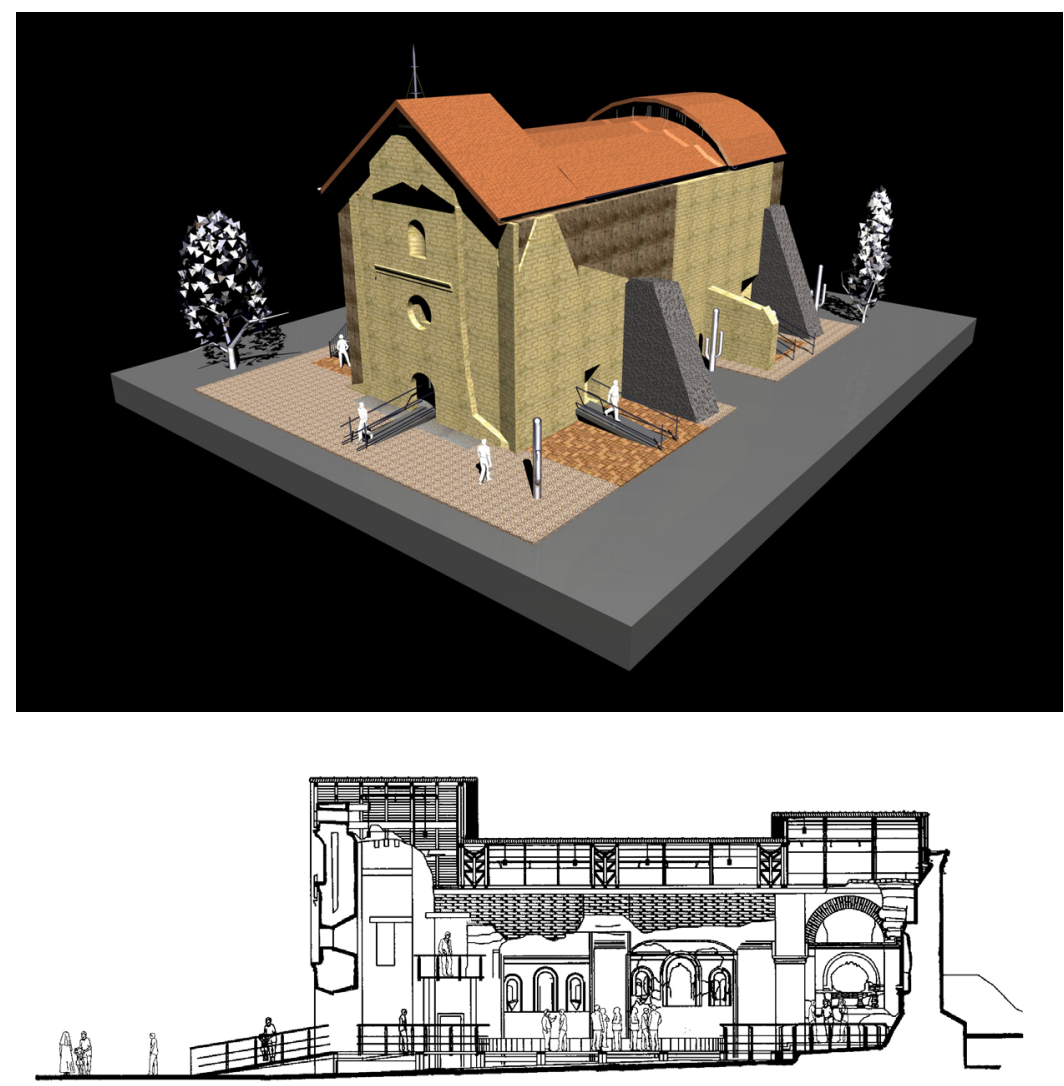

Figure 4: Top, a model of the new roof seen from the outside. Bottom, an interior view of the temple with the new roof.

- The new roof intends to recuperate the general volume the temple once had, without being the same. It also recreates the three different levels that the original roof had. The main idea is to insinuate the lines and forms of the primitive church, without reproducing them in a literal way, just in a similar manner. In this same way the trusses to support the roof structure retake the rhythm of the adobe ribs of the temple, which also obeys the structural logic of the building, exactly where the Franciscan reinforced the structure in order to sustain the roof.

- The trusses will support a wooden roof that will be covered on its exterior side with copper, which is a resistant material, lightweight, and gives a distinct finishing to the roof. The whole structure will be much lighter than the original roof and will not stress walls or foundations. The calculations show that the load at the base of the walls will be of $2.7 \mathrm{~kg} / \mathrm{cm}^{2}$, being much lower than the resistance detected in the test of the adobe. 
- Inside the temple the original floor was found; it is made with brick tiles of approximately $30 \times 30 \mathrm{~cm}$. These tiles must not be used as a floor, but as part of the archeological ruin. In order to not step on the original tile, a platform will be incorporated so that people visiting the temple may walk freely without causing any damage.

- The outside part of the temple, specifically the ruins of the baptistery, and the choir room will not be covered. In this case the top of the remaining walls will be protected with new adobe, and a brick crown.

- The main facade will be consolidated, injecting and filling cracks and restructured with steel cables to guarantee its stability and binding with the adobe nucleus.

- As far as the plumbing and electrical fixes are concerned, these elements will be used in the least amount possible. Gutters and pipes will take rain water properly to a filtration field. No pipes, tubes, lamps or other needed elements will be fixed on original pieces; all accessories must be supported exclusively on new elements.

\section{Conclusion}

The study of conservation and restoration systems for cultural heritage built with adobe is relatively recent, and much of the information and data as well as quality standards are in process of being discussed, evaluated and applied due to the variety of possible technical solutions.

Many of the tests done in relation with this material frequently do not consider the "organic" relationship of the constructive systems that originated them and that maintained them stable during centuries. Each component must be considered as a part of a system that has elements at a smaller scale, and they themselves are part of a bigger scale. There are many investigations about physical and chemical analysis that concentrate on clay as a construction material. These analyses have made important contributions over certain types of alterations and their causes. Nevertheless because they have an isolated view from the system as a whole, they do not recognize most of the problems and, consequently, the possible solutions for this kind of architecture, that has to do with the superstructure, the urban setting and sometimes even at a territorial scale [11].

When earth constructions are done correctly and the building has a proper maintenance, they are capable of surviving similar constructions built with more "prestigious" materials. However, in cases where the buildings have such a degree of decay that it makes understanding them difficult, it is necessary to turn to various considerations that may allow their conservation.

In this sense, there are a series of fundamental criteria in the general theory of heritage restoration that, thanks to its generality, allows the implementation of all kinds of structures. These criteria consider aspects such as authenticity, minimum intervention, best comprehension, the quest for the potential unit of the property, reversibility and distinction of the integrated parts. 


\section{References}

[1] ICOMOS, 1994, The Nara Document on Authenticity, Nara Conference on Authenticity in Relation to the World Heritage Convention, Nara, Japan, http://www.international.icomos.org/naradoc_eng.htm

[2] Jean-Louis Luxen, Jean-Louis, 2003, The intangible dimension of Monuments and sites, ICOMOS, $\mathrm{http} / / / \mathrm{www}$.international.icomos.org/luxen_eng.htm

[3] ICOMOS, 1964, Venice Charter, International charter for the conservation and restoration of monuments and sites, http://www.icomos.org/venice_charter.html

[4] UNESCO, 2005, Viena Memorandum, World heritage and contemporary architecture. Managing the historic urban landscape, http:// whc.unesco.org/uploads/activities/documents/activity-48-3.doc

[5] Kino, Eusebio Francisco, 1985, Crónica de la Pimería Alta. Favores Celestiales, Gobierno del Estado de Sonora, Hermosillo.

[6] Ivey, James, 1998, A preliminary structural history of Nuestra Señora del Pilar y Santiago de Cocospera, NPS; Mecanoescrito, Archivo técnico de la sección de Monumentos Históricos, Centro INAH Sonora, Hermosillo.

[7] Martínez, Júpiter, 2004, Cocóspera, sombras de adobe. Estudio arqueológico del templo de la misión de Nuestra Señora del Pilar y Santiago de Cocóspera, Sonora. Tesis para obtener el titulo de Licenciado en Arqueología, INAH- SEP, México D.F. p. 22.

[8] Pickens, Buford (Ed.), 1993, The missions of Northern Sonora: a 1935 fiel documentation, University of Arizona Press, Phoenix.

[9] Martínez, Júpiter, Op cit. p. 23

[10] Guerrero, Luis, 1994, Arquitectura de tierra en México, México D.F., U.A.M.-Azcapotzalco. p. 24.

[11] Guerrero, Luis, 2002, "Deterioro del patrimonio edificado en adobe", Revista Diseño y Sociedad, No. 13. Otoño, U.A.M.-Xochimilco, México. D.F. 2002, p.p. 4-11. 